\title{
Challenges Faced by Students with Hearing Impairment in Bulawayo Urban Regular Schools
}

\author{
*Gudyanga E \\ nwadesango@ufh.ac.za \\ **Wadesango $\mathrm{N}$ \\ ***Eliphanos Hove \\ *Gudyanga A \\ *Midlands State University, Faculty of Education, Gweru, Zimbabwe \\ ${ }^{* *}$ University of Fort Hare, TLC, East London, RSA \\ ***Zimbabwe Open University, Mat south, Zimbabwe
}

Doi:10.5901/mjss.2014.v5n9p445

\section{Abstract}

There is a risk of students with hearing impairment being excluded from the teaching and learning that goes on, unless measures are taken to make sure they are fully included. This prompted this desktop study on problems associated with the inclusion of hearing impaired students in secondary schools. The study established that besides communication problems, students experienced feelings of anger, frustration and isolation depending on the dictates of the environment. Literature revealed that learning is a process that happens under observable and ideal conditions to the extent that situations in which students are placed deliberately or otherwise had great effects on them. The review of literature focused on the problem and its context. It also emerged that there was an opportunity for teachers and other stakeholders to reflect on their school and classroom practices with hearing impaired students and adopt effective strategies of managing them in inclusive secondary schools.

Keywords: students, regular schools, urban, hearing impairment, specialist teachers,

\section{Background}

Children with hearing impairment may have partial or full hearing loss on one or both ears (Hardman et al, 2005).The characteristics exhibited by the students depend on the degree of hearing loss and the onset of that loss. According to Chimedza and Petersen (2003) the earlier the hearing loss manifests itself in a child, the more difficulty he or she will have in developing the spoken language. A hearing handicap or deafness involves not only the loss or impairment of hearing, but the loss or limitation of the ability to acquire language and speech naturally or spontaneously, (Kapp, 1991). Impaired or total lack of language has serious implications for the child's development.

It is worth noting that the characteristics of a child with mild hearing loss are in many ways more similar to a hearing child's than to a deaf child's characteristics. It causes a number of other serious problems that are linked to the inability to receive or express messages and thoughts, (Adoyo, 2008). According to Hetu, (1993) because of its insidious and hidden nature, hearing loss can be devastating. It can be particularly traumatic because it is often mistaken for absent mindedness or senility. For most learners, having a hearing loss threatens their self image and may manifest as feelings of inadequacy, being constraining to other people, being abnormal or handicapped. Most of the literature is in agreement about the feelings people experience when they lose their hearing.

Literature has shown that deaf children are less socially mature than hearing children and the gap between hearing and deaf children widens with increasing age (Marschark, 1993).It has been shown that deaf children and deaf adolescents generally have less positive ideas about themselves than do comparable groups of hearing peers. It has also been reported that there is a high incidence of emotional and behavioural problems in hearing impaired children of all ages (Meadow, 1980, Marschark, 1993). Reasons advanced for the difficulties of hearing impaired children include absence of interaction and appropriate mode of communication among these children and their hearing parents and 
peers (Marschark, 1993). The delayed language development experienced by most hearing impaired children results in more limited opportunities for effective and satisfying interaction, (Moores, 1996, Quigley and Paul, 1994). Unless a hearing impaired child has other disabilities such as brain damage, there is no causal relationship between deafness and intelligence. However, the child will be slow in reaching his or her full potential without early stimulation and training in communication, (Moores, 1996).

According to Adoyo (2008), language is not a necessary ingredient for complex cognitive processes. It is a misconception that the hearing impaired is limited in cognitive development. It has been proven that they are not delayed in visual-motor-perceptual functioning. This may be the case if brain damage is involved, but if the disability is solely in the hearing mechanism, then this appears to be false. Chimedza and Peterson, (2003) assert that it has been shown that deafness itself does not affect a person's intellectual capacity to learn and that deaf children have the normal range of intelligence when tested on performance rather than on verbal tests (Moores, 1996). There are studies which report that most children with hearing impairment experience low academic achievement, (Marschark, 1993, Densham, 1995). Chimedza and Petersen (2003) point out that this is particularly so in deaf students of hearing parents as compared to their hearing peers. The ability to read which lies heavily on the main language skills is cited as the main area affected, (Moores, 1996). Even at school leaving age, deaf students are still known to have poor reading attainment levels.

Generally, it appears that the child's social development (through socialisation) is closely related to his or her normative cognitive development. If the child's cognitive functioning is limited, or development is hampered by certain conditions such as hearing impairment, social and normative development will likewise be deficient, because the inadequate acquisition of insight into what is acceptable and unacceptable (abstract values) will cause problems, (Adoyo, 2008). By implication, the child's inability to hear may also impede the learning of various socially acceptable habits. Kapp (1991) contends that the hearing impaired child faces problems acquiring and understanding moral behaviour codes because it is mainly through language that they are transferred from one member of society to another. The deaf child's socialisation is deficient because inability to hear deprives the child of the most meaningful guidelines, for moulding of behaviour (Stinson and Whitmire,2000). Because of the inability to communicate freely and understand language properly, the child is largely isolated from his or her hearing contemporaries.

Deafness is often mistakenly associated with helplessness and the need for protection, hence the greatest obstacle facing the hearing disabled child or adolescent is not the hearing disability, but the failure of parents, professionals and the general public to understand and accept the person with this disability (Adoyo, 2008). Andrews and Lupart, (2000) found that students may be more fatigued than classmates due to listening effort needed, may have immature behaviour, barriers build with negative impact on self esteem as the child is accused of hearing when he or she wants to, "day dreaming", or "not paying attention". Child loses ability for selective hearing and has increased difficulty suppressing background noise which makes the learning environment stressful. Communication is significantly affected, and socialisation with peers with normal hearing becomes increasingly difficult. With full time use of hearing aids/ FM System the child may be judged as a less competent learner, resulting in poorer self concept, social immaturity and sense of rejection. The child may appear inattentive and frustrated. It appears deafness is a fundamental educational handicap because it interferes with normal linguistic and intellectual development. However, with proper support, most hearing impaired children can and do succeed in school, by so doing demystifying labels or stereotypes associated with hearing impairment. To this effect Al-zyoudi (2006) contends that every child has unique characteristics, interests, abilities and learning needs.

\section{The Ideal Teaching and Learning Environment for the Hearing Impaired Learners}

Some established theoretical models showing the importance of environmental factors in learning have been influential in education, (Aldoyo, 2008). Wearmouth and Reid, (2002) report on the influence of Brofenbrenner's model. It identifies four levels that influence children's learning outcomes. These are the microsystems, which is the immediate context of the child like the school, classroom and home), the exosystem, which is about the outside demands that affect children), and the macrosystem, which is about the cultural beliefs or institutional policies that influence individuals' behaviour. The ecosystem perspective indicates that the learning environment needs to be considered in the light of the students' needs and include all aspect s of the system described above as each can influence the educational outcome. Understanding the importance of the environment can minimise the effects of a learning difficulty and enhance performance and selfesteem (Reid, 2005). In regular secondary schools, there can be two groups of hearing impaired children, those wearing hearing aids and those whose hearing disability does not require them to wear assistive devices. Hearing aid users have residual hearing and the hearing aid brings their hearing almost to a normal level, through the amplification process (Tate, 1994). Some students may require lip reading to reach a normal level of comprehension and these will need preferential 
seating arrangements, (Chimedza and Peterson, 2003).

In an environment which is unsympathetic in acoustic terms, the hearing aids will pick up and amplify every detail of sound, irrespective of its relevance (Tate, 1994). The noisier the environment is, the more likely it is that the undesired noises will be amplified to the detriment of more important sounds, such as the teacher's voice, (Booth and Ainscow, 2003). Kapp (1991) points out that secondary school buildings and classrooms, should be designed and equipped in such a way as to harmonise with the personal and didactical needs of students they are to accommodate. The existing infrastructure at regular secondary schools offering inclusive education needs to be adjusted to accommodate all learners' needs. Chakuchichi, et al (2003) noted that the content of the least restrictive environment should be in the perspective of accessing the curriculum. The environment is least restrictive, if it facilitates the acquisition of knowledge and skills.

According to Stinson and Whitmire (2000), inclusion has profound effects not only on life in classrooms, but also on other aspects of school organisation and teaching: namely pupil grouping, curriculum structure, staffing, timetabling, pastoral care provision, the physical layout of the school, availability of ancillary help, links with specialist agencies, academic structure and the attitudes of staff and pupils. All of these interact to provide an environment in which students with hearing impairment are educated. In addition to completing academic tasks, the student has a need to be accepted as a social member of the teaching group and to be as independent in this situation as possible. Interaction with other students is important and the arrangement of furniture within the teaching area can do much to maximize these opportunities. Classroom design and layout have obviously great importance for these students who require the use of items of special equipment.

Ainscow, (1995) suggested the ideal physical environment for students with hearing impairment. The classrooms should be away from noise and controlled for acoustics that affect hearing aids. There is need to add carpets, window treatments, or acoustical wall/ ceiling coverings to absorb sound and reduce noise from furniture scrapping on hard surfaces by attaching rubber shoes to the legs of students' desks and chairs. The classrooms should also be well lit to enable the hard-of hearing and deaf students to speech read and to read the signing. Besides the acoustically treated classrooms, speech rooms and auditory training centres should be available. These are sound proofed and have special equipment to help in speech and auditory training and conducting audiometric tests at school level. The purpose of the various accommodations is to level the 'playing' field, (Someth and Lewin, 2005). Decisions as to which supplementary aids and services, accommodations, modifications or supports are appropriate for a particular student, are to be made on an individualised basis, even at secondary school level, (Adayo, 2008). According to Moores and Martins (2006), the study conducted on noise factors and illumination, reported that, a certain level of working noise is tolerated particularly where students are using a variety of resources or working on group tasks. According to the students, few classrooms were carpeted and low level of working noise in regular schools can cause problems for students who rely on hearing aids because all sounds are picked up and amplified by an aid.

Mushoriwa and Gasva (2008) say that parents and teachers should try to understand the problem of the students and try to cooperate with them in helping their navigation of the learning process and work output. In class, a teacher should try to speak slowly and clearly so that they can easily understand the lesson. While teaching, a teacher should stand at one place, so that he or she engages the attention of students with hearing disabilities so as not to distract them with constant movement. In a study reported by Adoyo (2008) it was revealed that teachers should use the latest techniques and materials for instruction when working with children with hearing impairment. More emphasis should be laid on showing the practical things to students, so that they can easily understand the lesson. Teachers should make diagrams on the chalkboard for explaining the things. If a student with hearing disability asks a question, the teacher should remain calm and answer the question slowly and clearly to provide clarity. Students should be encouraged to express themselves freely in the class. Teachers should try to develop activities that involve all the children together. This helps to keep a healthy and collaborative interaction of students with hearing impairment with their peers in the classroom. It also helps in creating a better social adjustment for them in daily classroom interactions. With the proper care and instruction, children with hearing disabilities can have a positive and productive experience in any learning environment.

According to Moss (1995), the early and consistent use of a system of total communication serves as a springboard for intellectual development and subsequent academic achievement. Communication methods will likely vary according to the skills of the student as well as the curriculum content. The most convincing study to support teaching the deaf total or manual communication is reported by Stinson and Whitmire (2000). It appeared that total communication or manual communication are more effective for the hearing impaired students, and that it at least gives them a means of communicating that is superior to the oral approach. It calls for the teacher, therefore to be thoroughly familiar with all the techniques available to teach the hearing impaired. Moss (1995) contends that most of the same teaching strategies used 
to instruct children who do not have a disability would be appropriate for the students with a hearing impairment. The students would learn from what they see and do (action). They learn a great deal incidentally by watching others. The teacher may also rely on print, pictures, gestures, and movements to support or give instructions. Stinson and Whitmire (2000) suggest the arrangement of the classroom so that students with hearing impairment can see facial expressions, read lips, and assess body language of the educator and other students and provide preferential seating. The teacher should repeat questions and comments from the other students and allow the use of index cards to communicate. Provisions for written or captioned school announcements should be availed. They further suggest the provision of sign language or oral interpreting services, consideration of the use of different words or phrases to express the same thought and providing the student with lecture notes. Inclusion of basic sign language training in the classroom curriculum was also suggested.

On the same note Adoyo (2008) suggest more key teaching adaptations for students with hearing impairment. These include adapting the regular classroom materials (e.g. different textbooks), planning assignments and activities that allow mainstreamed hearing impaired students to be successful, providing individual instruction (e.g. plan for one-onone sessions),making adaptations for students when developing daily plans (e.g. be alert to problems that could pose special difficulties to stunts),providing extra time (e.g. for skill reinforcement) and adapting pacing of instruction (e.g. break down material into smaller segments). Reed (2008) asserts that hearing impaired students are more likely to succeed in regular education classrooms if they receive targeted support services in the classroom. Collaboration between general and special education teachers is of necessity, (Hegarty, 1993),especially considering that inclusion of hearing impaired students may be stalled by an education system that is not fit to include them because of the barriers of lack of knowledge, lack of will, lack of vision and lack of resources, (Hodkinson and Vickerman, 2009).

\section{Teacher Attitudes Towards the Inclusion of Hearing Impaired Students in Regular Secondary Schools}

The influence of teacher attitudes emanates from the fact that the individual classroom teacher remains the most effective variable to influence the performance of students. The inclusion of children with hearing impairment does not depend solely on whether the child is severely or profoundly deaf, or the level of intelligence or the ability to lip read, language development, or availability of resources but also on teachers' attitudes (Booth and Ainscow, 2002). Sacks, (2001) reports of a study which revealed that the regular teachers were least prepared for inclusive education of children with disabilities. The teachers had little training in dealing with individual differences and specific instructional processes developed for special needs students. The roles and responsibilities of regular education teachers were never clearly defined in this process. These teachers and their regular education students were not prepared for the inclusion of children with disabilities.

Chadha's (1999) study regarding inclusion as it existed in India showed that regular education teachers generally did not support inclusion, nor did they believe they possessed the competency necessary to effectively instruct students with special needs. The study showed that the teachers did not believe the regular classroom was the setting in which these students' needs could be adequately met. Among the groups of special needs students who received negative responses from teachers were the hearing impaired and the intellectually challenged students. The most dominant view emerging from survey studies conducted is that teacher acceptance or resistance to the inclusion of students with disabilities into general education classrooms is related to the knowledge base and experiences of teachers, (Sacks, 2001). According to Florian et al, (2004), many schools resist the pressure to become inclusive, because they are concerned that doing so will have a negative impact on the academic progress of other students and lower academic standards. Indeed, this is surprising given that, Britain is among the first pioneers of inclusive education.

Booth and Ainscow (1998) found in the Netherlands that many students with hearing impairment who had been included in regular classes wanted to go back to their special schools after suffering stigmatization and isolation. This is in line with some studies conducted in developing countries (e.g. by Mushoriwa and Gasva, 2008) which found negative attitudes by regular teachers and pupils towards inclusion. The chief argument against inclusion was that not only does inclusion interfere with the learning of mainstream students, but also that inclusion accentuates the students' disabilities as some of the children will have problems in performing some of the activities of the regular class. Hergarty, (1994) reports that in quite a number of studies, teachers' attitudes toward educating pupils with special needs has been put forward as a decisive factor in making schools more exclusive. Teachers have been described as becoming more frustrated, domoralised and distressed by not being able to cater for the increased diversity of needs in their regular classrooms.

Petersen's (1994) study of regular teachers' attitudes towards the inclusion of hearing impaired students in Australia investigated classroom behaviour of hearing impaired students; perceived ability to teach hearing impaired 
students; classroom management with hearing impaired students and academic and social growth of hearing impaired students. The study ascertained that the teachers from both the schools had generally positive attitudes towards the integration of hearing impaired students. The teachers strongly supported the belief that the regular class was superior academically, socially and emotionally to the separate special class. Teachers also felt that many of the things they did with regular students were appropriate for hearing impaired students. They were of the opinion that the inclusion of these students would foster the acceptance of differences on the part of the regular school population. Petersen's (1994) study illustrates that although the issue of inclusion of hearing impaired students is still fraught with controversies, attitudes seem to be gradually shifting in the positive direction. Mushoriwa and Gasva's (2008) study provides evidence that mainstream secondary school students are accepting to the inclusion of students with disabilities.

All-zyoudi's (2006) study of teachers' attitudes towards inclusive education in Jordanian schools indicates a greater willingness among teachers to include children with certain types of disabilities such as physical disabilities rather than students with mental retardation and hearing impairment that affect reading, writing, arithmetic and behaviour. The nature and the severity of the disabilities influence the attitudes of the teachers. Teachers surveyed ranked the needs of children with emotional and behavioural difficulties as most difficult to meet, followed by children with learning difficulties, followed by children with visual impairment and followed by children with a hearing impairment. Other factors related to teachers' attitudes are training, gender and grade level taught. It was found that high school teachers displayed more positive attitudes towards inclusion than primary school teachers. Mushoriwa and Gasva's (2008) study showed that teachers at schools with inclusion with resource room support had more positive attitudes towards inclusion of students with disabilities than those at schools with unplanned inclusion. The positive attitudes may be influenced by the regular education teacher getting support from the resource room teacher. Studies that have involved teachers' attitudes towards inclusion indicate that this area is still dicey and shrouded with discrepancies and controversies. Some studies conducted report positive attitudes while others report to the contrary. There is very little information on teachers' attitudes towards the inclusion of hearing impaired students in regular secondary schools.

\section{Practices that Facilitate the Inclusion of Hearing Impaired Students in Secondary School}

The concept of inclusion implies a sense of belonging and acceptance, (Chakuchichi et al, 2002), a positive response to individual differences (Pijl, Meijer and Hegarty (1997) and developing inclusive environments that promote educational success for all students (Hodkinson and Vickerman,2009) however, the physical placement of students with hearing impairment in regular secondary schools is often overemphasised, while other aspects of developing inclusive environments are neglected ( Chimedza and Peterson, 2003). A key factor in the inclusion of hearing impaired students in regular secondary schools is resource mobilization (Chimedza and Peters, 2001).Starting with the recognition that many students with hearing impairment are still excluded from education for reasons based on lack of resources there is need to ensure that adequate resources are made available( Chakuchichi et al,2003).Resources does not only refer to teaching methods and materials but also to time available for instruction and to the knowledge and skills of teachers acquired through training and experience ( Pijl, Meijer and Hergarty, 1997). Attending to the needs of various students with hearing impairment implies that there should be profound changes in the curriculum, methodology and organization of the schools in order to accommodate the needs of all learners (Hergarty, 1994). Curriculum includes structures, practices and organization within schools and the social relationship which students foster and sustain as well as what is taught, the way teaching takes place and the way in which pupils are organised for learning (Adoyo, 2008). The curriculum needs to be inclusive. Although hearing impaired students follow the same curricular as their hearing counterparts have extra subject they do in order to help them access the co-curricular.

The resource needs of hearing impaired students who wear hearing aids and those who have a profound hearing loss and need a back up support from a special teacher should be available in inclusive settings. The peripatetic teacher assists the students in some of the subjects and with technical language which may give the student some difficulty. The students are served through inclusion with clinical remediation, ( Mushoriwa and Gasva, 2008). The degree of special help required and the availability of inclusion with clinical remediation from teachers and remedial tutors from Schools Psychological Services may decide whether a child may remain in a regular secondary school or needs more, (Ainscow, 1995). An important feature of secondary schooling is that of departmentalized teaching where students have different teachers for different subjects, (Chimedza and Peterson, 2003). The situation may present difficulties for students with hearing impairment as they would need to adjust to multiple teachers' speech and teaching styles. Career choices often start being made at this level of education. In view of this the hearing impaired students' talents and abilities may have to be nurtured possibly at the expense of academic work (Reed, 1994). In an inclusive education system human resources is essential and it includes all the people who support learning of hearing impaired students. Successful inclusion requires 
a definition of roles and responsibilities, collaboration and building of teams and training, (Ainscow, 1995). Teachers need to be willing to adjust their plans and their practices in the light of the feedback they receive from their learners with hearing impairment.

There is need to offset physical difficulties for hearing impaired students in secondary schools ( Reed, 2004). The students move from room to room and it is unlikely that acoustic conditions will be good, Hergarty, (1993) observed that the physical environment of the school is critical to the inclusion of students with hearing impairment as it determines what the school can do in the teaching and learning of these students. The need for modifications in resource rooms and ordinary classrooms cannot be overemphasised. The rooms should be acoustically treated with carpets, double glazing windows and sound proof doors so as to minimise reverberations (Tate, 1994). There is need for speech rooms, auditory training centres and testing rooms where audiometric tests are carried out. There is need for attitude change towards inclusion. Negative attitudes are detrimental to the teaching and learning of students with hearing impairment. Both teachers and parents should have an attitude of acceptance, respect and valuation of the individual differences of students with hearing impairment in regular secondary schools, (Chimedza and Peterson, 2003). They need to acknowledge that all students can learn and they all need support (Hodkinson and Vickerman,2009). Inclusion of students with hearing impairment is about enabling education structures, systems and the learning methodologies to meet their needs (Chakuchichi et al, 2003). Specific policies for special education play a valuable role in schools in providing guidelines for actions and procedures. Having a specific inclusion policy for hearing impaired students in regular secondary schools is necessary to secure inclusion within the schools' developmental plans and ensure the implementation of inclusive practices. Specifically an inclusive policy would address issues like discrimination, harassment, negative attitudes and issues of access and the physical environment of the school (Corbett, 2001)

According to Chimedza and Peterson (2001) to avoid harm to the academic education of students with hearing impairment in regular secondary schools full panoply of services and resources is required. These include adequate supports and services for the student, well designed educational programmes, professional development for all teachers involved, general and special educators alike and reduced class size based on the severity of the students' needs. In addition there is need for professional skill development in the area of cooperative learning, peer tutoring and adaptive curriculum, collaboration between parents, teachers and administrators. There is need to provide sufficient funding so that schools would be able to develop programmes for students based on student need instead of the availability of funding. The challenge of inclusion without support is that it may amount to "child dumping" and can be more frustrating than segregated services, (Chakuchichi et al, 2003).

\section{Conclusion}

The second chapter reviewed literature thematically. Most of the literature reviewed was in agreement about the feelings students with hearing impairment experience when placed in inclusive secondary school settings. Besides communication problems, students experienced feelings of anger, frustration and isolation depending on the dictates of the environment. Literature revealed that learning is a process that happens under observable and ideal conditions to the extent that situations in which students are placed deliberately or otherwise had great effects on them. Also literature on teacher attitudes towards the inclusion of hearing impaired students indicated that this area is still dicy and shrouded with controversies and discrepancies. Lastly, practices that facilitate the inclusion of hearing impaired students were contingent on skills of teachers, the needs of learners and the availability of resources.

\section{Recommendations}

- Basing on the research findings, the following recommendations are made:

- Students with hearing impairment served through inclusion with clinical remediation need to take the full curriculum in ordinary classrooms and receive clinical remedial instruction as needed.

- Policies that would guide the inclusion of learners with hearing impairment in secondary schools need to be put in place.

- Further research on the inclusion of students with hearing impairment in secondary schools at a wider scale is recommended. 


\section{References}

Adoyo, P.O. (2008). Educating Deaf Children in an Inclusive setting in Kenya: Challenges and Considerations. Nairobi: University of Kenya.

Ainscow, M.(1995). Education for All: Making it happen, Support for Learning 10 (4) 147-155.

Al-Zyoudi, E. (2006). Teachers' Attitudes towards Inclusive Education in Jordanian schools, International Journal of Special Education, 21 (2): $23-31$

Andrews, J. and Lupart, J. (2000). The inclusive classroom: Educating Exceptional Children. London: Nelson Thomson.

Booth, T. and Ainscow, M. (2003). The index for Inclusion. (2nd Edition). Bristol: Centre for studies on Linguistic Education.

Chadha, A. (1999). The Inclusive Initiative in India, Journal of International Association of Special Education 3, No. 1 31-35.

Chakuchichi, D. D. Chimedza, R. M. Chiinze, M. M. and Kaputa, T. M. (2003). Including the Excluded. Issues in Disability and Inclusion. Harare: Zimbabwe Open University.

Chimedza, R. and Peters, S. (2001). Disabilities and Special Needs Education in an African Setting. Harare: College Press.

Corbett, J. (2001). Teaching Approaches Which Support Inclusive Education. A Connective Pedagogy. British Journal of Special Education, 28 (2) 55-59.

Florian, L. Rouse, M. Black-Hawkins, K. and Jull, S. (2004). "What can National Data Sets tell us about Inclusion and Pupil Achievement", British Journal of Special Education, 31 (3) :115-121

Hardman, M. I. Drew, G. L. and Egan, M. W. (2005). Human Exceptionality in Society, School and Family. Boston: Allyn and Bacon.

Hegarty, S. (1993). Meeting Special Needs in Ordinary Schools. London: Cassell Educational Limited.

Hetu, R. (1993). The impact of acquired Hearing impairment on intimate relationships. Implications for Rehabilitation. Audiology, 33:363381.

Hodkinson, A. and Vickerman, P. (2009). Key Issues in Special Educational Needs and Inclusion. London: Sage.Johnson.D. (1994). Research Methods in Educational Management. London: Longman Group UK Ltd.

Kapp, J. A. (1991). Children with problems: An Orthopedagogical Perspective. Pretoria: Ivan Schank Marschark N, (1993). Removing the Barriers in Deaf Education, Australian Journal of Education of The Deaf, 12 (2):23-19

Moores, D.F. (1996). Educating the Deaf: Psychology, Principles and Practices (4th Edition). Boston: Houghton Mifflin Company.

Moores, D.F. and Martins, D.S. (2006). Deaf Learners: Developments in curriculum and Instruction.Washington: Gallaudet University Press.

Moss. (1995). Teaching Strategies and Content Modifications for the child with Deaf- Blindness. Edition of P.S.News

Mushoriwa,T. and Gasva, O.(2008). Attitudes of Secondary School pupil towards the inclusion of Educably Mentally Challenged pupils in Harare in The Zimbabwe Bulletin of Teacher Education.ISSN, 1022-3800 Vol 15, Issue 1.

Peterson, J. (1994). Regular Teachers' Attitudes towards the Integration of Hearing Impaired Students. A Government High Schools Educational Research: Innovation and Practice 2: 2-14.

Pijl, S. P. Meijer, J. M. and Hegarty, S. (1997). Inclusive Education. London: Routledge.

Quigley, S. P. and Paul, V. P. (1994). Language and Deafness. San Diego: Singular Publishing group.

Reed, M. (1994). Educating Hearing Impaired Children in Ordinary and Special Schools. Milton Keyness: Open University Press.

Reed, G. (2004). Learning Styles and Inclusion. London: Paul Chapman Publishing.

Sacks, A. (2001). Special Education: Contemporary Education Issues.Oxford:ABC-Clio,Inc.

Someth, B. and Lewin, C. (2005). Research Methods in the Social Sciences. New Delhi: Sage Publications.

Stinson, M.S. and Whitmire, K.A. (2000). "Adolescents who are deaf or hard of Hearing: A Communication Perspective on Educational Placement": Topics in Language Disorder, 20 (2): 58-73.

Tate, C. (1994). Principles of Hearing Aid Audiology. London: Glassgow Chapman and Hall. 